\title{
Bioinspired nanostructured spiderweb for high-efficiency capturing and killing of bacteria
}

\author{
Wei Wang ${ }^{1,2}$, Bin $\mathrm{Yu}^{1,3}$, Wenbo Sun ${ }^{1,4}$, Chunhuan Jiang ${ }^{1,2^{*}}$ and Lehui $\mathrm{Lu}^{1,2^{*}}$
}

\begin{abstract}
Antibacterial nanoagents with broad-spectrum antibacterial activities have emerged as an evolution of antibiotics. However, their bacteria-capturing capability and bacteria-killing efficiency remain insufficient for commercial implementation. Inspired by the hunting behavior of spiders, here, a novel spiderweb-like nanoagent based on silver-adenine nanowires is designed to achieve high-efficiency capture and killing of bacteria. By virtue of the initiative bacteriacapturing functionality, this spiderweb-like nanoagent could effectively attract and trap bacteria through electrostatic interaction and its reticular morphology feature. Furthermore, its synergetic antibacterial mechanism combining physical membranolysis with reactive oxygen species (ROS) release allows such nanoagent to harvest a promoted bactericidal activity. Importantly, the woundplast employing the spiderweblike nanoagent exhibits a superior antibacterial efficacy against drug-resistant Gram-negative Escherichia coli and Gram-positive methicillin-resistant Staphylococcus aureus compared with commercially available woundplasts. This work may pave a new way for rational design of new generation bactericidal agents facing the future super-bacteria booming.
\end{abstract}

Keywords: bioinspired nanoagent, antibacterial activity, bacteria capturing, nanostructured spiderweb

\section{INTRODUCTION}

The infection issues caused by pathogenic bacteria, causing hundred thousand of deaths worldwide annually, have attracted increasing public attention as a medical challenge [1-5]. Up to date, treatment paradigms rely heavily on antibiotics in most instances of daily healthcare and clinic therapy [6-8]. Unfortunately, as the result of long-term abuse and overuse of antibiotics, the emergence of the multidrug-resistant bacteria decreases the therapeutic efficacy of the conventional antibiotics or even makes them useless under many circumstances $[9,10,11,12]$. Therefore, novel potent antibacterial materials are highly desirable to reduce the extensive uses of antibiotics $[13,14]$.

Antibacterial nanoagents have emerged as an evolution of antibiotics with broad-spectrum antibacterial activities and are expected to take the place of antibiotics these years $[15,16]$. However, their bacteria-capturing capability and bacteria-killing efficiency remain insufficient for clinical implementation [1721]. Typically, nanoagents are presumed to perform the antibacterial effect via two dominant mechanisms: the first involves generating strong interactions with bacteria to disrupt the cell membrane [22-24] and the second involves producing poison species, such as reactive oxygen species (ROS), to disturb the cell metabolism $[1,6,25,26]$. Nevertheless, not only the inadequate probability of contact between nanoagents and bacteria causes difficulty to exert the abundant potency, but also the bacterial movement makes nanoagents be not able to act on the pathogens persistently, ultimately resulting in a moderate antimicrobial effect. On the other hand, the inherent drawbacks of poison species, such as short lifespan and limited diffusion distance of ROS, usually lead to an unsatisfactory infection eradication $[20,27,28]$. Thus, high-efficiency capturing of bacteria to shorten their acting distance and enhance the contact efficiency are pivotal prerequisite to improve bactericidal activity of nanoagents [29].

Web-weaving spiders, neither with wings nor agile mobility, provide a fascinating example of hunting insects via spiderweb by which they can effectively capture flying insects and kill them with venom quickly. Inspired by this hunting behavior, an efficient antibacterial nanoagent could be designed by integrating both "spiderweb" and "venom" functional moieties. Here, we demonstrate the feasibility of a novel spiderweb-like nanoagent based on silver-adenine nanowires as a high-efficiency bactericide. Up to date, silver (Ag) and its derivatives are the most commonly used bactericidal nanoagents and have been approved as additives in many commodities [30-35]. However, despite the wide spread, the application of Ag-based antibacterial materials remains a controversial subject due to their insufficient potency and the potential toxicity of released $\mathrm{Ag}^{+}$ ions towards mammal cells [19,31,36,37]. Here, to fabricate Agbased spiderweb-like antibacterial nanoagents, the biocompatible adenine is introduced as the linker. Adenine, one kind of nucleotides containing several nitrogen $(\mathrm{N})$ sites in the molecular structure [38], has been reported to present strong coordination effect towards $\mathrm{Ag}^{+}$ions and thus could facilitate the formation of a crosslinked spiderweb-like structure [39]. Moreover, the strong coordination between adenine and $\mathrm{Ag}^{+}$

\footnotetext{
${ }^{1}$ State Key Laboratory of Electroanalytical Chemistry, Changchun Institute of Applied Chemistry, Chinese Academy of Sciences, Changchun 130022, China

${ }^{2}$ University of Science and Technology of China, Hefei 230026, China

${ }^{3}$ University of the Chinese Academy of Sciences, Beijing 100039, China

${ }^{4}$ College of Materials Science and Engineering, College of Chemistry and Chemical Engineering, Shandong Sino-Japanese Center for Collaborative Research of Carbon Nanomaterials, Instrumental Analysis Center of Qingdao University, Qingdao University, Qingdao 266071, China

* Corresponding authors (emails: lehuilu@ciac.ac.cn (Lu L); chunhuanjiang@ciac.ac.cn (Jiang C))
} 
could lead to a remarkable retardation effect towards $\mathrm{Ag}^{+}$ion release, and thus diminish the toxicity towards normal tissues. Additionally, in the physiological environment, the $\mathrm{N}$ sites tend to protonate and thus endow the nanomaterial with a positive surface charge, which would provide additional "venom" potency besides $\mathrm{Ag}^{+}$via the electrostatic adsorption towards negative-charged bacteria and a membrane-lytic antibacterial process $[21,22,40,41]$. In this study, the as-designed spiderweblike antibacterial nanoagents (Ag-adenine nano-spiderwebs (AgA NSWs)) present excellent capturing and killing efficacy towards both Gram-positive and Gram-negative bacteria. Excitingly, Ag-A NSWs also present higher potency towards resistant bacteria species compared with common antibiotics. Moreover, wound healing experiment results confirm that the woundplast employing Ag-A NSWs exhibits outstanding performance in killing bacteria, eliminating inflammation and promoting wound healing.

\section{EXPERIMENTAL SECTION}

\section{Materials}

Adenine was purchased from Aladdin Reagent. Silver nitrate $\left(\mathrm{AgNO}_{3}, \geq 99.0 \%\right)$ was purchased from Sigma-Aldrich. Terephthalic acid (TA) was purchased from Beijing Chemicals. 2,7Dichlorodi-hydrofluorescein diacetate (DCFH-DA) was purchased from Beyotime Inst. Biotech. LIVE/DEAD ${ }^{\circledR}$ BacLight $^{\mathrm{TM}}$ Bacterial Viability Kits (STYO 9 \& propidium iodide (PI)) were obtained from Invitrogen Detection Technologies. All the reagents were used without further purification.

\section{Synthesis of Ag-A NSWs}

Adenine $(1 \mathrm{mmol})$ was dissolved in $\mathrm{N}, \mathrm{N}$-dimethylformamide (DMF) $(80 \mathrm{~mL})$ in a $250-\mathrm{mL}$ round-bottom flask, followed by heating at $140^{\circ} \mathrm{C}$ to form a transparent solution. Then, $\mathrm{AgNO}_{3}$ $(1 \mathrm{mmol})$ was added into DMF to form a $20 \mathrm{~mL}$ solution avoiding light, and the above solution was mixed under $1000 \mathrm{r} \mathrm{min}^{-1}$ stirring. The obtained solution was stirred at $140^{\circ} \mathrm{C}$ for $2 \mathrm{~h}$ without light irradiation. After cooling down to room temperature, the Ag-A NSWs were collected by centrifugation, and then washed with water and ethanol for several times. Finally, the samples were dried at $80^{\circ} \mathrm{C}$ overnight.

\section{.OH detection assay}

TA was selected to indicate the generation of $\cdot \mathrm{OH}$. Five groups of samples including TA $\left(0.5 \mathrm{mmol} \mathrm{L}^{-1}\right), \quad \mathrm{Ag}$-A NSWs $\left(0.0625 \mathrm{mg} \mathrm{mL}^{-1}\right)+\mathrm{TA}, \mathrm{Ag}-\mathrm{A}$ NSWs $\left(0.125 \mathrm{mg} \mathrm{mL}^{-1}\right)+\mathrm{TA}$, and Ag-A NSWs (0.25 mg mL $\left.{ }^{-1}\right)+$ TA, Ag-A NSWs $\left(0.5 \mathrm{mg} \mathrm{mL}^{-1}\right)+$ TA were investigated. All groups were incubated at room temperature for $2 \mathrm{~h}$. Whereafter, the fluorescence of the samples was measured by using $312 \mathrm{~nm}$ as excitation wavelength, and the emission at a wavelength of $425 \mathrm{~nm}$ is related with $\cdot \mathrm{OH}$ production.

\section{Preparation of bacterial samples for SEM}

The bacteria-nanospiderweb samples were washed with phosphate buffer saline (PBS), fixed with 2.5\% glutaraldehyde for $1 \mathrm{~h}$, and then washed with PBS for three times, followed by dehydration with sequential treatment of $25 \%, 50 \%, 75 \%$ and $100 \%$ $\mathrm{C}_{2} \mathrm{H}_{5} \mathrm{OH}$ for $5 \mathrm{~min}$. Finally, a drop of bacterial suspension was put onto the silicon wafer and observed by scanning electron microscope (SEM).

\section{Evaluation of Ag divulgation in PBS}

The Ag-A NSWs (2 mL) solution with a concentration of $100 \mu \mathrm{g} \mathrm{mL}^{-1}$ was added in a dialysis tube (molecular weight cutoff: 1500), which was then placed in $400 \mathrm{~mL}$ of PBS under stirring. One milliliter of PBS solution was sampled and supplemented with the same volume of fresh PBS daily for $24 \mathrm{~h}$. The concentration of Ag was measured using inductively coupled plasma-optical emission spectroscopy (ICP-OES).

\section{Live/dead fluorescent staining}

Both methicillin-resistant Staphylococcus aureus (MRSA) and Escherichia coli (E. coli) bacterial cells were firstly treated with Ag-A NSWs for $1 \mathrm{~h}$. Afterwards, SYTO 9 and PI were added to incubate for $15 \mathrm{~min}$ at room temperature in the dark, and subsequently washed with PBS. Finally, the live/dead bacterial cells were then observed by confocal laser scanning microscope (CLSM).

\section{Determination of ROS generation in cells}

The intracellular ROS generation was monitored by using DCFH-DA. E. coli cells were firstly cultured overnight. Afterwards, Ag-A NSWs $\left(1 \mathrm{mg} \mathrm{mL}^{-1}\right)$ and DCFH-DA $\left(10 \mu \mathrm{mol} \mathrm{L}^{-1}\right)$ were added to incubate for $30 \mathrm{~min}$, while the unloaded probe was subsequently washed by PBS. Finally, the generation of intracellular ROS was observed by CLSM.

Evaluation of antibacterial activity against drug-resistant bacteria The spread plate method was employed to evaluate the antibacterial activity of Ag-A NSWs compared with chloramphenicol. After treatment with the same concentration $\left(0.05 \mathrm{mg} \mathrm{mL}^{-1}\right)$ of the proposed material and chloramphenicol as well as PBS, respectively, the E. coli K-12 strains were cultured on agar plate for $24 \mathrm{~h}$ at $37^{\circ} \mathrm{C}$.

\section{Woundplasts model antibacterial experiments}

The bacteria were diluted to $\sim 10^{6} \mathrm{CFU} \mathrm{mL}^{-1}$ and then inoculated on each group of woundplast cotton and treated for $6 \mathrm{~h}$ at $37^{\circ} \mathrm{C}$. After treatment, the woundplast cotton was cultured in $3 \mathrm{~mL}$ of Luria-Bertani (LB) medium under shaking at $180 \mathrm{rmin}^{-1}$ and $37^{\circ} \mathrm{C}$ over $18 \mathrm{~h}$, and $50 \mu \mathrm{L}$ of the obtained solution was added onto the agar plate and cultured for $24 \mathrm{~h}$ at $37^{\circ} \mathrm{C}$, respectively.

\section{In vivo treatment of MRSA-infected wounds}

Firstly, the mice (ICR, 6-8 weeks, 18-22 g) were slashed for a $\sim 12 \mathrm{~mm}^{2}(d=4 \mathrm{~mm})$ wound on the back and injected with $1 \times$ $10^{8} \mathrm{CFU} \mathrm{mL} \mathrm{m}^{-1}$ of MRSA bacteria. The mice with bacteriainfected wounds were separated and treated by different groups of woundplast containing the proposed model and three commercial woundplasts for seven days, respectively. Meanwhile, clean cotton was used as the control group. The wounds were observed and photographed, and the woundplasts were replaced every day. All the animal experiments were conducted in agreement with the guidelines of the Animal Study Committee of Changchun Institute of Applied Chemistry, Chinese Academy of Sciences. All efforts were made to minimize suffering of the mice.

\section{Evaluation of Ag divulgation on the wound tissue}

After seven days of therapy, the mice in different groups were sacrificed and the wound tissues were harvested. The sample was decomposed, and then analyzed by the ICP. 


\section{RESULTS AND DISCUSSION}

Synthesis and characterization of Ag-A NSWs

As illustrated in Scheme 1, the designed antibacterial material was fabricated by one-pot complexing of adenine and $\mathrm{AgNO}_{3}$ in DMF. Transmission electron microscopy (TEM) images showed that the as-synthesized product was composed of cross-linked nanofibers with a diameter of 5-10 nm (Fig. 1a, b). The formation of cross-linked structure could be attributed to the coordination interaction between $\mathrm{Ag}^{+}$ions and adenine that provided several nitrogen sites for the coordination effect [39]. Additionally, in the physiological environment, the $\mathrm{N}$ sites tended to protonate and thus endowed the nanomaterial with a positive surface charge, which would promote the electrostatic adsorption towards negative-charged bacteria and a membranelytic antibacterial process $[22,40,41] . \zeta$-potential result presented that Ag-A NSWs displayed a positive charge of $+30.1 \mathrm{mV}$ in accordance with the above prediction (Fig. 1d). As this tangled structure was similar to that of spiderweb, the generated product was termed as Ag-A NSW in the rest text. Then, the Ag-A NSW was carefully characterized by element mapping, Fourier transform infrared spectra (FT-IR), X-ray photoelectron spectra (XPS) and ICP-OES (Fig. 1e, $\mathrm{f}$ and Figs S1-S4, see details in the Supplementary information). As measured with ICP-OES, the mass ratio of Ag contents in the Ag-A NSWs was $17.39 \mathrm{wt} \%$. The obvious elemental distribution of $\mathrm{Ag}, \mathrm{C}$ and $\mathrm{N}$ on the mapping image verified the successful synthesis of coordination nanoweb (Fig. 1c).

\section{Antibacterial performance of Ag-A NSWs}

To evaluate the antibacterial performance of Ag-A NSWs, a minimum inhibitory concentration (MIC) assay was conducted towards E. coli with a double broth dilution method. As shown in Fig. S5, Ag-A NSWs presented a low MIC value in the range of $5-10 \mu \mathrm{gL}^{-1}$, which was comparable to that of reported $\mathrm{Ag}$ nanoparticles (diameter: 7, 29, and $89 \mathrm{~nm}$ ) [34]. Moreover, a significant decrease of optical density at $600 \mathrm{~nm}\left(\mathrm{OD}_{600}\right)$ was found when the bacteria cells were treated with Ag-A NSWs for

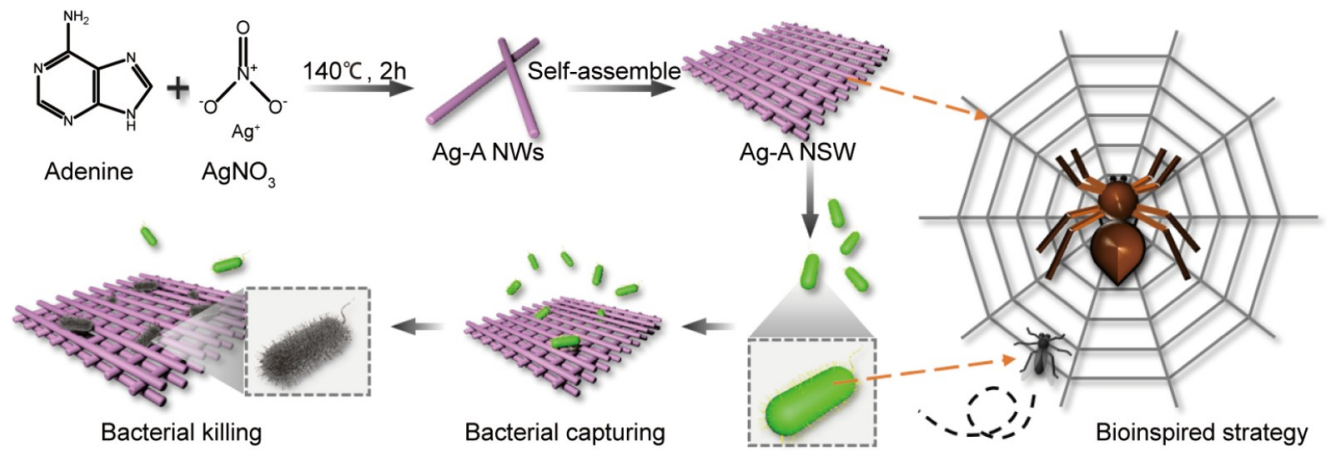

Scheme 1 Schematic illustration for construction of the Ag-A NSW antibacterial system inspired by the spiders and its capturing and killing properties for bacteria.
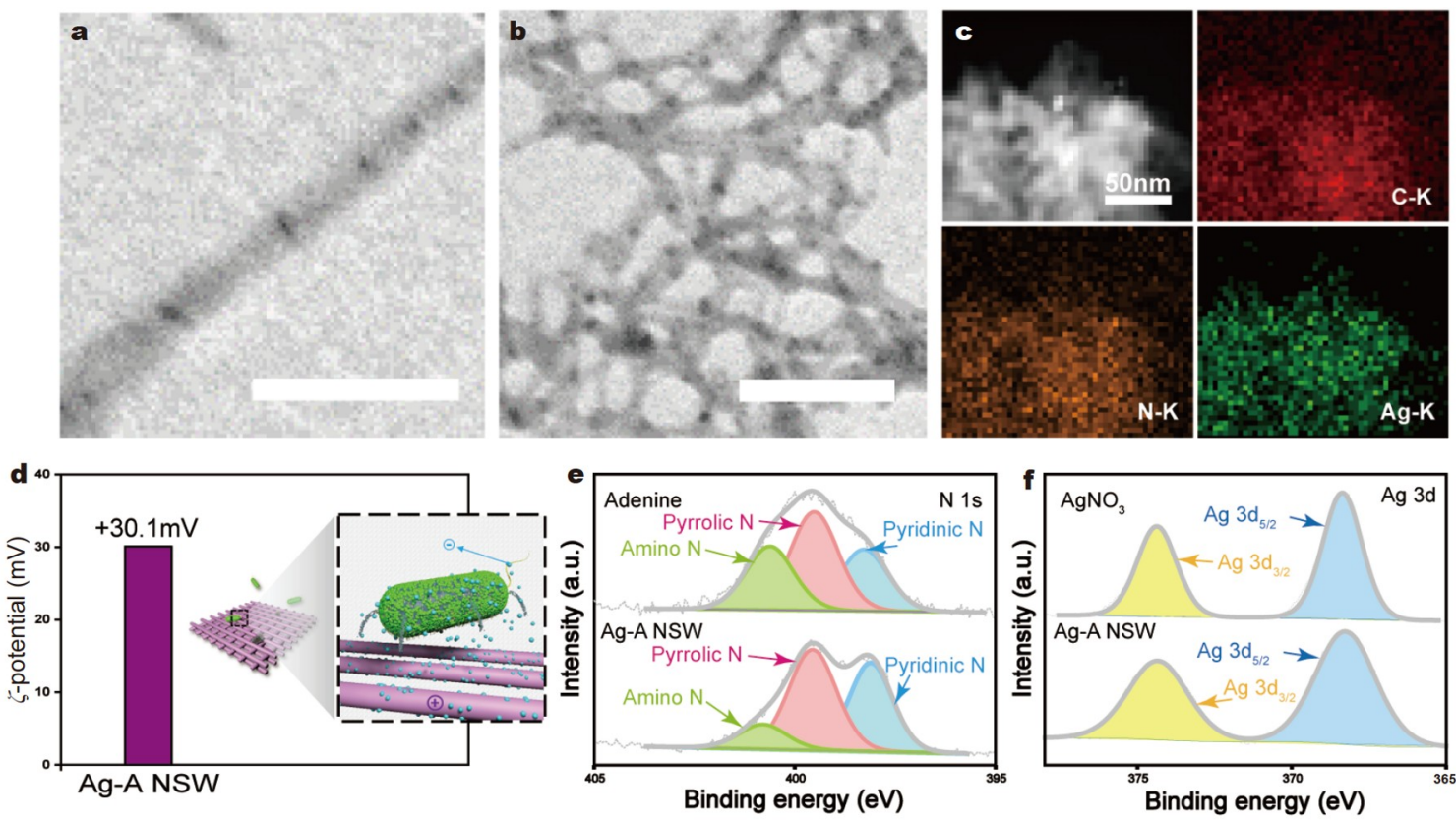

Figure 1 (a) TEM image of a single Ag-A NW. Scale bar: $100 \mathrm{~nm}$. (b) TEM image of Ag-A NSWs. Scale bar: $200 \mathrm{~nm}$. (c) High-angle annular dark-field scanning TEM image and the corresponding energy dispersive X-ray spectroscopy (EDS) mapping of Ag-A NSWs. (d) $\zeta$-potential and (e, f) XPS spectra of adenine, $\mathrm{AgNO}_{3}$ and $\mathrm{Ag}-\mathrm{A}$ NSWs. 
$6 \mathrm{~h}$ (Fig. S6) [42]. To investigate the bactericidal process, SEM was used to analyze the morphological change. As shown in Fig. 2a, Ag-A NSWs presented a time-dependent bactericidal manner. After $2 \mathrm{~h}$ of incubation, the typical rod-shaped structure with intact and smooth membrane turned wrinkled and collapsed. As the incubation time extended to $4 \mathrm{~h}$, large holes could be observed on the surface of E. coli cells, and the bacterial membrane and structure got severely ruptured. During this process, cytoplasm may leak out and become a major causal factor for bacterial death. Thus, a membrane-lytic antibacterial mechanism was proposed for Ag-A NSWs. Of additional note is that, the bacterial cells tended to aggregate during the bactericidal process. This phenomenon demonstrated the anticipatory adsorption effect between the positive-charged Ag-A NSWs and the negative-charged bacterial membrane.

To extend the evaluation of antibacterial capability of Ag-A NSWs, antibacterial assessment was also conducted towards a representative Gram-positive bacterial, Staphylococcus aureus. As a result, similar structural deformation could be observed with the increasing incubation time and concentration of Ag-A NSWs (Fig. 2b). The MIC value towards Staphylococcus aureus was measured to be $25-50 \mu \mathrm{g} \mathrm{mL}^{-1}$ (Fig. S5). The relatively higher MIC compared with that towards E. coli could be ascribed to the difference in the composition of cell external membrane between Gram-positive and Gram-negative bacteria. The difference in MIC between Gram-positive and Gram-negative bacteria has been commonly reported for several kinds of Ag-based bactericidal agents [34]. All these results, taken together, demonstrated a potent and broad-spectrum antimicrobial capacity of Ag-A NSWs towards both Gram-positive and Gram-negative bacteria.

In order to gain further insight into the membrane rupturebased antibacterial process, fluorescence-based Live/Dead assays were applied by employing the mixture of green-fluorescent
STYO 9 and red-fluorescent PI. STYO 9 generally labels both the bacteria with intact membranes and damaged membranes. In contrast, PI only penetrates bacteria with damaged membranes, resulting in a severe reduction in the STYO 9 staining and thus an integral red fluorescence. As shown in Fig. 2c, untreated $E$. coli cells exhibit dominant green fluorescence, proving that the cells mainly stayed alive. Then, the red fluorescence gradually became prominent with the increasing concentration of Ag-A NSWs, verifying that serious membrane rupture happened. Moreover, this concentration-dependent antibacterial manner elucidated that the bacterial inactivation was directly related with the presence of Ag-A NSWs. Additionally, it was worth noting that these two fluorescence regions distributed in nonuniform manners, especially when high concentrations of Ag-A NSWs were used. As shown in Fig. 2c, dead bacterial cells accumulated seriously and formed a large red fluorescencestained region. The accumulation of dead cells was consistent with that observed in SEM images, and both of these results suggested a correlation between cell death and bacterial fixation. In contrast, lived cells (green fluorescence-stained) tended to disperse randomly in the image except the red-stained region. The distinct distribution manner for dead and lived cells implied that bacterial capture and adhesion played important roles in the antibacterial process.

\section{Antibacterial mechanism of Ag-A NSWs}

To analyze the mechanism underlying the efficient antibacterial capability of $\mathrm{Ag}-\mathrm{A}$ NSWs, the release of $\mathrm{Ag}^{+}$ions was firstly monitored, because it was usually the main mechanism for Agbased antibacterial projects. Interestingly, it was found here that there was hardly any released $\mathrm{Ag}^{+}$in the first $6 \mathrm{~h}$. Importantly, there was only $1.65 \% \mathrm{Ag}$ leaked from the initial Ag-A NSWs solution even after incubation for $24 \mathrm{~h}$. This result implied that
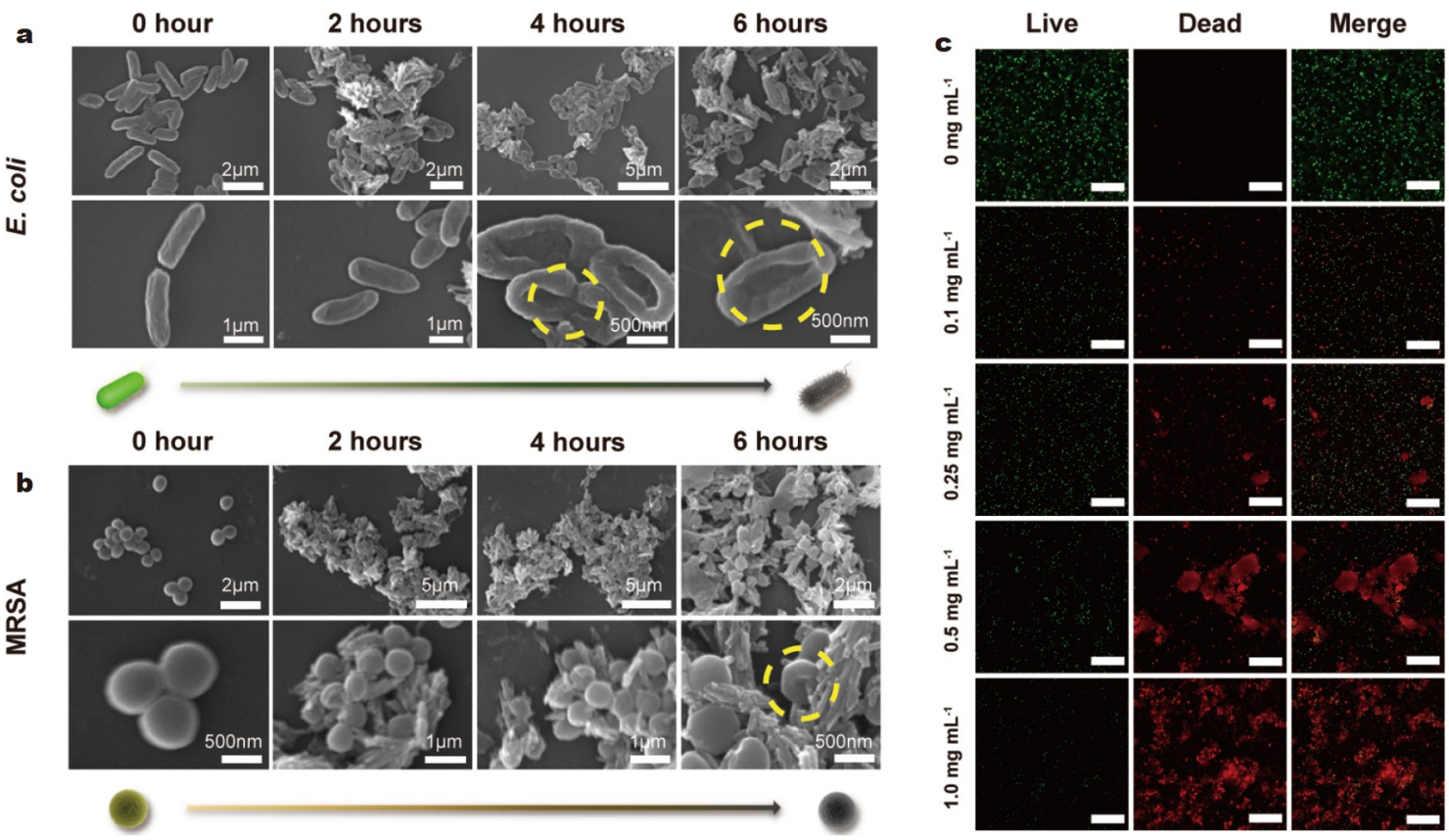

Figure 2 (a) Typical SEM images of the E. coli cells exposed to Ag-A NSW treatment for different durations. (b) SEM images of the MRSA cells exposed to Ag-A NSW treatment for different durations. Yellow circles mark the deformation of the bacteria cells. (c) CLSM images of E. coli treated with different concentrations of Ag-A NSWs. The red fluorescence (stained by PI) represents dead bacterial cells, and the green fluorescence (stained by STYO 9) represents live bacterial cells. Scale bars: $50 \mu \mathrm{m}$. 
the Ag-A NSWs present strong $\mathrm{Ag}^{+}$fixation capacity (Fig. S7). The promising retardation effects towards $\mathrm{Ag}^{+}$ion release could be ascribed to the strong interaction between $\mathrm{Ag}^{+}$ions and adenine which contains several $\mathrm{N}$ sites for coordination with $\mathrm{Ag}^{+}$ ions. Moreover, it is reported that $\mathrm{Ag}^{+}$ions at low concentrations are safe for mammalian cells [43]. Based on our results and previously reported literatures, we speculated that such a low dosage of released $\mathrm{Ag}^{+}$could hardly present any assistant for the bactericidal process, and thus ruled out the $\mathrm{Ag}^{+}$ion releasebased antibacterial mechanism. Even though the antibacterial capacity decreased, the relative side toxicity originating from released $\mathrm{Ag}^{+}$ions could simultaneously be expected to diminish.

Next, as another antibacterial pathway of Ag, the capacity in ROS production of Ag-A NSWs was evaluated. Firstly, TA was employed to analyze the generation of $\cdot \mathrm{OH}$ by monitoring their fluorescent product, 2-hydroxy TA (TAOH) [44]. As shown in Fig. $3 \mathrm{a}$, the fluorescence intensity increased gradually with the concentration of Ag-A NSWs, suggesting that the $\cdot \mathrm{OH}$ species were mainly generated from Ag-A NSWs. Then, we further evaluated the intracellular ROS generation by using DCFH-DA staining. It was found that, the intracellular ROS level (green fluorescence) was much higher in bacteria treated with Ag-A NSWs than in untreated bacteria (Fig. 3b), and escalation of green fluorescence was related with the concentration of Ag-A NSWs (Fig. S8). Based on all the above results, the antibacterial mechanism for Ag-A NSWs could be concluded to a combination of bacterial capture, membrane rupture and ROS release.

\section{Bacterial resistance evaluation of Ag-A NSWs}

Up to date, in response to living stress, various bacterial resistance mechanisms have been discovered in pathogenic bacteria against antibiotics. The increasing number of deaths caused by resistant bacteria infection has posed a great challenge to public health [45-47]. Thus, the antibacterial capacity towards resistant bacteria becomes one of the most important requirements for newly developed antibacterial materials. Impressively, both the Staphylococcus aureus and E. coli used here are resistant strains with high tolerance towards methicillin and chloramphenicol, respectively. Thus, the obtained low MIC presented a potentially potent antibacterial efficiency of Ag-A NSWs towards resistant strains. In order to gain further evidence, antibacterial capacity against huge amount of resistant E. coli infection was parallelly examined towards three agar-plates spread with Ag-A NSWs, chloramphenicol, and saline solution. As shown in Fig. 4, barely any difference in the number of $E$. coli colonies could be identified between the saline and chloramphenicol groups, suggesting inappreciable inhibition effect of chloramphenicol. In contrast, distinct decrease of bacteria could be observed when incubated with Ag-A NSWs, suggesting a potent antibacterial efficiency towards resistant bacteria.

Apart from the bacterial resistance towards traditional antibiotics, the resistance against new generational nano-agents has also been widely investigated. For instance, to eliminate the toxicity of $\mathrm{Ag}^{+}$ions, an active efflux mechanism was developed in mutant strain and reduced the toxicity from intracellular $\mathrm{Ag}^{+}$
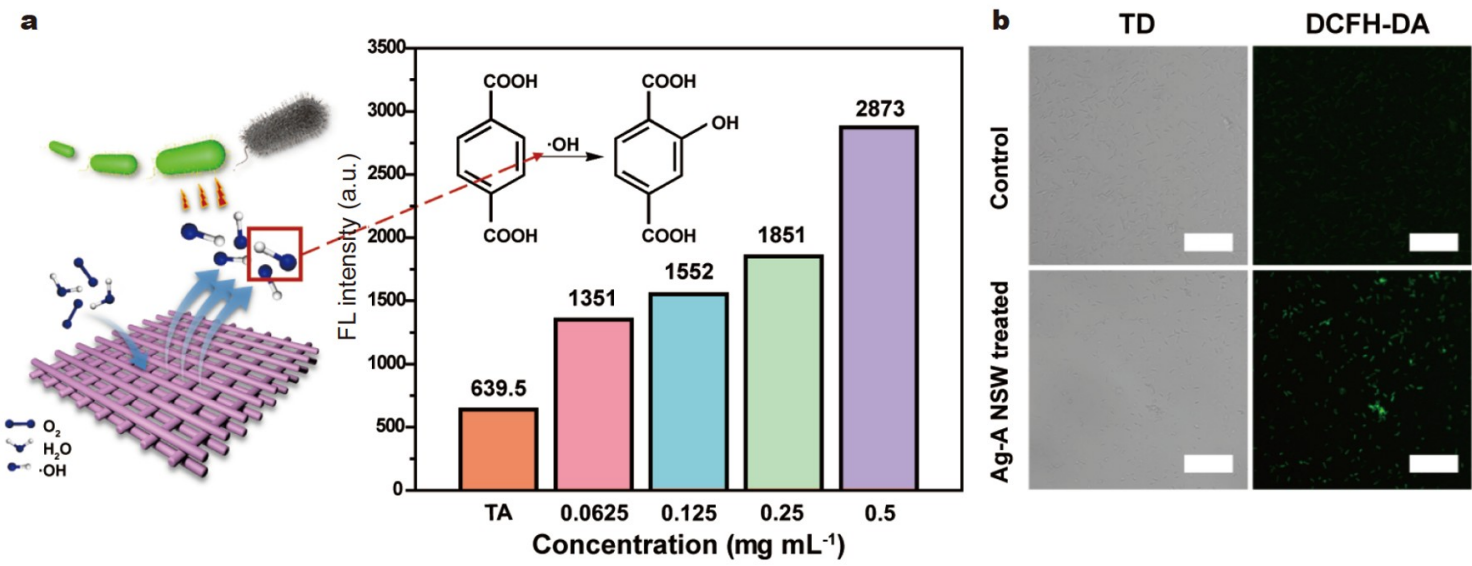

Figure 3 (a) The fluorescent intensity for TA detection of hydroxyl radicals from different groups of Ag-A NSW addition. (b) Intracellular ROS assay of $E$. coli treated with Ag-A NSWs. Scale bars: $50 \mu \mathrm{m}$.

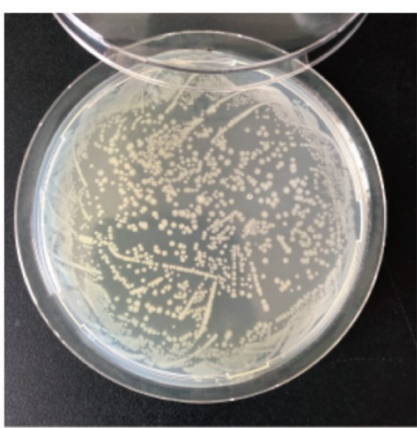

Control

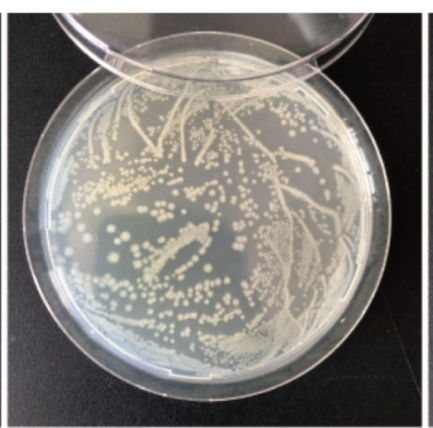

Chloramphenicol

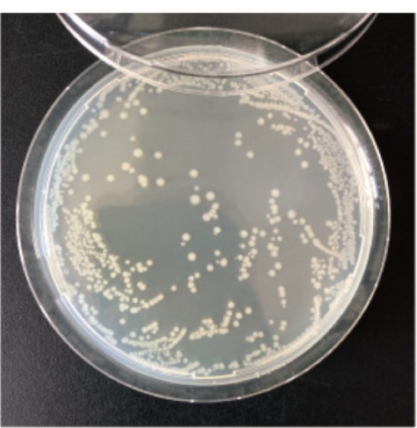

Ag-A NSW

Figure 4 Images of drug-resistant E. coli colonies treated with chloramphenicol and Ag-A NSWs on the LB agar plates. 
ions. Recently, it has been reported that, bacteria could present resistance against Ag nanoparticles through a phenotypic change. During the repetitive administration of nonfatal concentration of Ag nanoparticles, bacterial flagellin was produced, which caused the aggregation of Ag nanoparticles and thus increased their tolerance to Ag nanoparticles [19]. Therefore, we further evaluated whether Ag-A NSWs could induce bacterial resistance by a proof-of-concept experiment. Interestingly, the MIC towards E. coli maintained almost steady at $5-10 \mu \mathrm{g} \mathrm{mL}^{-1}$ in five generations, indicating that no bacterial resistance was stimulated. This excellent performance could be ascribed to special combining antibacterial mechanisms. Firstly, the membranelytic antibacterial process was a physical mechanism which was reported to have less possibility in stimulating bacterial resistance [48]. Secondly, because of the strong coordination between $\mathrm{Ag}^{+}$and adenine in the Ag-A NSWs, neither the $\mathrm{Ag}^{+}$ions nor the Ag nanoparticles could leach out and trigger the bacterial resistance. This property is of great importance, especially in facing with the current challenge of super-bacteria booming.

\section{Antibacterial application of Ag-A NSWs}

Encouraged by the promising antibacterial properties of Ag-A SNWs, we then evaluated their performance in a practical application model, woundplast. Woundplast is the most convenient antibacterial commodity and has been widely used as treatment for cutaneous wounds. Apart from the traditional function of preventing unexpected pollution, there is an increasing appeal of bacterial inhibiting in the infected wound, especially in those wounds infected with resistant strains. Here, to examine the capability of Ag-A NSWs in inhibition of bacterial proliferation, a woundplast based on Ag-A NSWs was primarily fabricated by using cotton as the antibacterial material carrier. The woundplast was firstly inoculated with Gramnegative strain E. coli in a concentration of $10^{6} \mathrm{CFU}$, and allowed to incubate at $37^{\circ} \mathrm{C}$ overnight. Then, the E. coli cells on the woundplast were subsequently rinsed and inoculated on an LBagar plate. Finally, the bacteriostatic potency could be represented by the number of the colony in the plate. As expected, in stark contrast to the untreated woundplast, hardly any E. coli colony could be observed on the agar plates of the Ag-A NSWbased woundplast group, suggesting a satisfactory bacteriostatic potency. Simultaneously, three commercial woundplasts as a comparison were also evaluated with the same procedure (Fig. 5a, b). As a result, all these commercial woundplasts exhibited inappreciable antibacterial potency against E. coli. Moreover, these commercial woundplasts presented nearly no antibacterial efficiency when faced with intractable resistant MRSA (Fig. 5c). On the contrary, barely any MRSA colony could be observed in the Ag-A NSW-based woundplast group. The superior inactivation efficiency against both E. coli and MRSA clearly verified the broad-spectrum antibacterial effect of the Ag-A NSW woundplast compared with those commercial woundplasts. Most importantly, the Ag-A NSW-based woundplast maintained its high bacteriostatic potency towards intractable resistant MRSA. Thus, the Ag-A NSW-based woundplast provided a promising antibacterial alternative, especially facing with superbugs in the near future. Combining with the property of being free of bacterial resistance stimula-
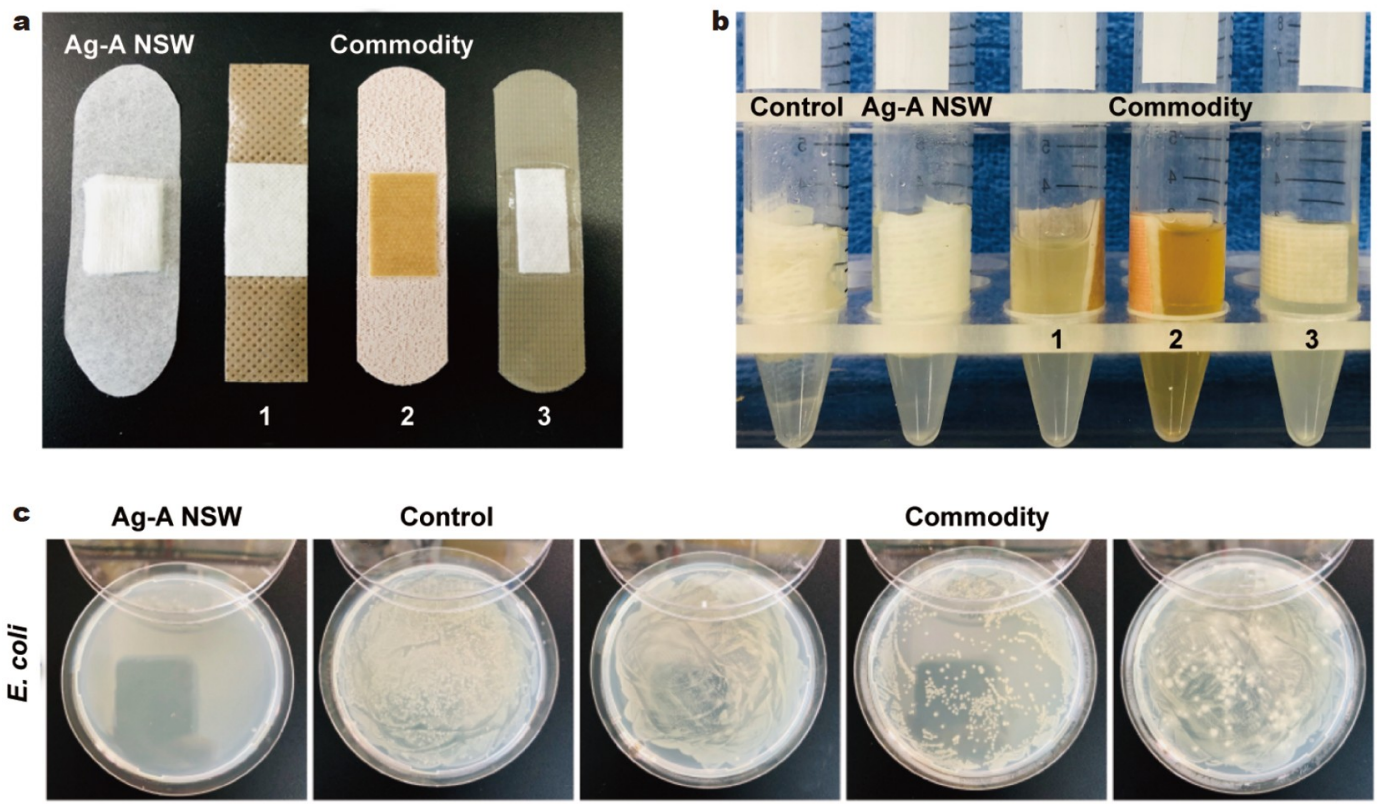

1

2
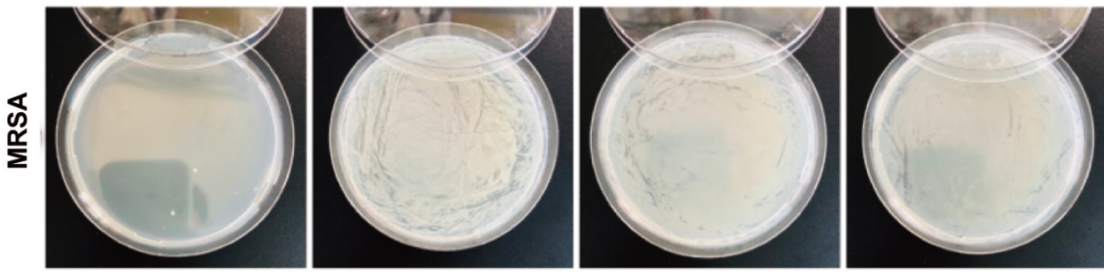

3

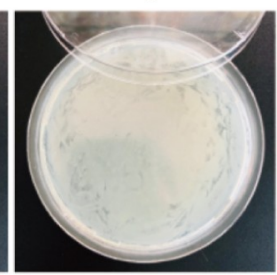

Figure 5 (a) The novel Ag-A NSW woundplast model and the widely used commercial woundplasts (1-3). (b, c) The evaluation of E. coli and MRSA growth separated from different groups of woundplasts and cultured on agar plates. 


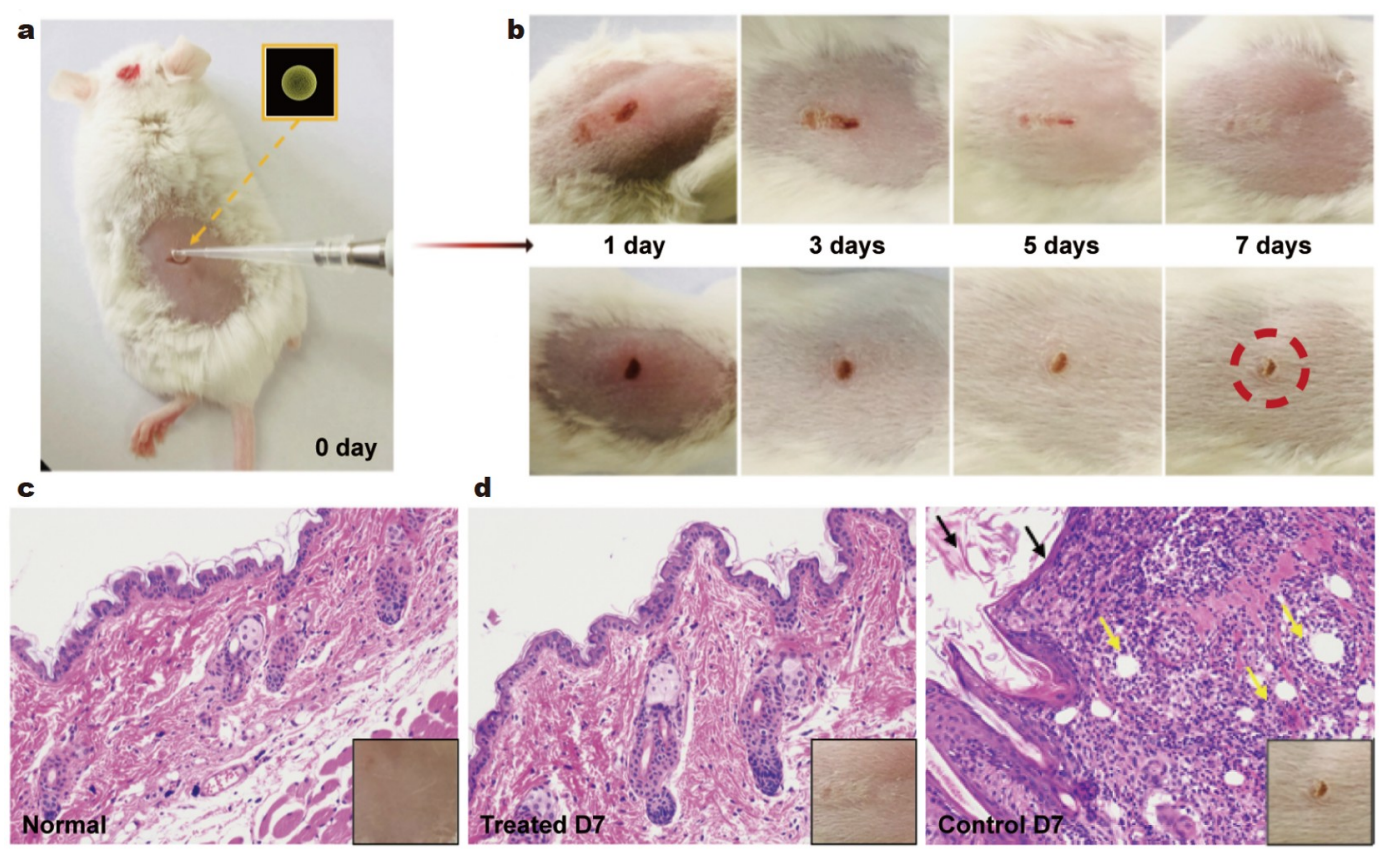

Figure 6 (a) Photographs of MRSA-infected wounds on mice after different durations of therapeutic process. (b) H\&E staining of normal skin tissue slices. (c) H\&E staining of skin tissue slices treated with the Ag-A NSW woundplast model at $7^{\text {th }}$ day. (d) H\&E staining of skin tissue slices from the control group at $7^{\text {th }}$ day. Black arrows indicaee the epidermis of the injured tissue was significantly thinned. Yellow arrows indicate the neutrophils infiltrated. Insets in (b-d) show the wound tissue.

tion, the wide application of Ag-A NSWs could be expected.

To examine the capacity of the Ag-A NSW woundplast to improve wound healing in vivo, a conceptual wound model infected with resistant MRSA was built on mice. Before this evaluation, the stability of Ag-A NSWs in physiological environment was ensured by TEM images after the stability test in PBS solution for $24 \mathrm{~h}$ (Figs S9 and S10) [49]. Further, the systemic influence from Ag-A NSW woundplast was assessed with routine blood test (Fig. S11). The results presented that all the main components in the blood from the Ag-A NSW woundplast-treated group maintained similar levels with that of normal mice, implying acceptable biosafety. This could be partly ascribed to the neglectable $\mathrm{Ag}^{+}$ion release (Fig. S12). Then, the mice were separated into three groups: treated with the saline-soaked cotton (i), Ag-A NSW woundplast (ii), and commercial woundplasts (iii: $1 \#, 2 \#, 3 \#$ ). The wound healing process was monitored during a week. As a result, the group treated with the Ag-A NSW woundplast presented an accelerated wound healing process compared with those treated with saline-soaked cotton and commercial woundplasts. Newly formed scab appeared even in the first day of treatment, and significant improvement in wound healing could be observed after five days of treatment with the Ag-A NSW woundplast by the evidence of scab peeling and cambium appearing (Fig. 6a). In contrast, the wounds treated with both the saline-soaked cotton and commercial woundplasts maintained uncovered and presented inflammatory swollen at the same time (Fig. S13). All these results suggested a potent efficacy of the Ag-A NSW woundplast in promoting the wound healing process. Impressively, hair coverage was observed on the healed wound after seven days of treatment, implying that the function of skin tissue had recovered to initial condition. To further evaluate the wound healing process, histological analysis was conducted by hematoxylin and eosin (H\&E) staining and Masson staining (Fig. 6b-d and Fig. S14). At the $7^{\text {th }}$ day post-treatment, there were still plenty of inflammatory cells remaining in the wound treated with saline-soaked cotton (Fig. 6d). In contrast, intact epidermal layer could be observed in the Ag-A NSW woundplast group, as well as less infiltrated inflammatory cells in the wound site. All these results, taken together, demonstrated the important effect of the Ag-A NSW woundplast in eliminating inflammation and promoting wound healing.

\section{CONCLUSIONS}

In summary, we have fabricated a novel bioinspired spiderweblike nanoagent (Ag-A NSWs) with high antibacterial efficiency based on the coordination effect between silver and adenine. Taking advantage of the positive surface charge derived from the protonated N sites, Ag-A NSWs could effectively attract and trap bacteria through electrostatic interactions and decrease the interaction distance between bacteria and the poison species. As a result, Ag-A NSWs presented significantly higher antibacterial potency and superior broad-spectrum antimicrobial activities compared with widely-used antibiotics. Furthermore, novel antibacterial woundplast was fabricated based on Ag-A NSWs, which exhibited preferable therapeutic efficacy for bacteriainfected wounds in mice compared with commercial woundplasts. All these results indicate that the proposed system provides a new strategy for developing antibacterial nanoagents and possesses broad prospects for application in commercial implementation and clinic therapeutics.

Received 17 May 2021; accepted 22 June 2021; published online 26 August 2021

1 Rizzello L, Pompa PP. Nanosilver-based antibacterial drugs and devices: Mechanisms, methodological drawbacks, and guidelines. Chem Soc Rev, 2014, 43: 1501-1518 
2 Li X, Bai H, Yang Y, et al. Supramolecular antibacterial materials for combatting antibiotic resistance. Adv Mater, 2018, 1805092

3 Yang Y, Deng Y, Huang J, et al. Size-transformable metal-organic framework-derived nanocarbons for localized chemo-photothermal bacterial ablation and wound disinfection. Adv Funct Mater, 2019, 29: 1900143

4 Wang L, Zhang X, Yang K, et al. A novel double-crosslinking-doublenetwork design for injectable hydrogels with enhanced tissue adhesion and antibacterial capability for wound treatment. Adv Funct Mater, 2019, 30: 1904156

5 Jones KE, Patel NG, Levy MA, et al. Global trends in emerging infectious diseases. Nature, 2008, 451: 990-993

6 Shan J, Li X, Yang $\mathrm{K}$, et al. Efficient bacteria killing by $\mathrm{Cu}_{2} \mathrm{WS}_{4}$ nanocrystals with enzyme-like properties and bacteria-binding ability. ACS Nano, 2019, 13: 13797-13808

7 Kim W, Zhu W, Hendricks GL, et al. A new class of synthetic retinoid antibiotics effective against bacterial persisters. Nature, 2018, 556: 103107

8 Cao $\mathrm{F}$, Zhang $\mathrm{L}$, Wang $\mathrm{H}$, et al. Defect-rich adhesive nanozymes as efficient antibiotics for enhanced bacterial inhibition. Angew Chem Int Ed, 2019, 58: 16236-16242

9 D'Costa VM, King CE, Kalan L, et al. Antibiotic resistance is ancient. Nature, 2011, 477: 457-461

10 Van Boeckel TP, Gandra S, Ashok A, et al. Global antibiotic consumption 2000 to 2010: An analysis of national pharmaceutical sales data. Lancet Infect Dis, 2014, 14: 742-750

11 Zhang M, Zhang C, Zhai X, et al. Antibacterial mechanism and activity of cerium oxide nanoparticles. Sci China Mater, 2019, 62: 1727-1739

$12 \mathrm{Wu} \mathrm{F}$, Zheng $\mathrm{H}$, Wang $\mathrm{W}$, et al. Rapid eradication of antibiotic-resistant bacteria and biofilms by MXene and near-infrared light through photothermal ablation. Sci China Mater, 2021, 64: 748-758

13 Yeom J, Guimaraes PPG, Ahn HM, et al. Chiral supraparticles for controllable nanomedicine. Adv Mater, 2020, 32: 1903878

14 Zhao X, Guo B, Wu H, et al. Injectable antibacterial conductive nanocomposite cryogels with rapid shape recovery for noncompressible hemorrhage and wound healing. Nat Commun, 2018, 9: 2784

15 Miller KP, Wang L, Benicewicz BC, et al. Inorganic nanoparticles engineered to attack bacteria. Chem Soc Rev, 2015, 44: 7787-7807

16 Zhu X, Radovic-Moreno AF, Wu J, et al. Nanomedicine in the management of microbial infection-Overview and perspectives. Nano Today, 2014, 9: 478-498

17 Courtney CM, Goodman SM, McDaniel JA, et al. Photoexcited quantum dots for killing multidrug-resistant bacteria. Nat Mater, 2016, 15: 529-534

18 Liu C, Kong D, Hsu PC, et al. Rapid water disinfection using vertically aligned $\mathrm{MoS}_{2}$ nanofilms and visible light. Nat Nanotech, 2016, 11: 1098-1104

19 Panáček A, Kvítek L, Smékalová M, et al. Bacterial resistance to silver nanoparticles and how to overcome it. Nat Nanotech, 2018, 13: 65-71

20 Yu Z, Sun Q, Pan W, et al. A near-infrared triggered nanophotosensitizer inducing domino effect on mitochondrial reactive oxygen species burst for cancer therapy. ACS Nano, 2015, 9: 11064-11074

21 Cao F, Ju E, Zhang Y, et al. An efficient and benign antimicrobial depot based on silver-infused $\mathrm{MoS}_{2}$. ACS Nano, 2017, 11: 4651-4659

22 Yan S, Chen S, Gou X, et al. Biodegradable supramolecular materials based on cationic polyaspartamides and pillar[5]arene for targeting gram-positive bacteria and mitigating antimicrobial resistance. Adv Funct Mater, 2019, 29: 1904683

$23 \mathrm{Tu}$ Y, Lv M, Xiu P, et al. Destructive extraction of phospholipids from Escherichia coli membranes by graphene nanosheets. Nat Nanotech, 2013, 8: 594-601

24 Zhu J, Wang J, Hou J, et al. Graphene-based antimicrobial polymeric membranes: A review. J Mater Chem A, 2017, 5: 6776-6793

25 Li Y, Zhang W, Niu J, et al. Mechanism of photogenerated reactive oxygen species and correlation with the antibacterial properties of engineered metal-oxide nanoparticles. ACS Nano, 2012, 6: 5164-5173

26 Yu B, Ai K, Lu L. Dual-protective nano-sunscreen enables high-efficient elimination of the self-derived hazards. Appl Mater Today, 2020, 18:
100493

27 Kadiyala U, Kotov NA, VanEpps JS. Antibacterial metal oxide nanoparticles: Challenges in interpreting the literature. Curr Pharm Des, 2018, 24: 896-903

28 Fan W, Huang P, Chen X. Overcoming the Achilles' heel of photodynamic therapy. Chem Soc Rev, 2016, 45: 6488-6519

29 Liu L, Chen S, Xue Z, et al. Bacterial capture efficiency in fluid bloodstream improved by bendable nanowires. Nat Commun, 2018, 9: 444

30 Eckhardt S, Brunetto PS, Gagnon J, et al. Nanobio silver: Its interactions with peptides and bacteria, and its uses in medicine. Chem Rev, 2013, 113: 4708-4754

31 Richter AP, Brown JS, Bharti B, et al. An environmentally benign antimicrobial nanoparticle based on a silver-infused lignin core. Nat Nanotech, 2015, 10: 817-823

32 Alexander JW. History of the medical use of silver. Surgical Infections, 2009, 10: 289-292

33 Wiechers JW, Musee N. Engineered inorganic nanoparticles and cosmetics: Facts, issues, knowledge gaps and challenges. J Biomed Nanotechnol, 2010, 6: 408-431

34 Chernousova S, Epple M. Silver as antibacterial agent: Ion, nanoparticle, and metal. Angew Chem Int Ed, 2013, 52: 1636-1653

35 Zheng K, Setyawati MI, Lim TP, et al. Antimicrobial cluster bombs: Silver nanoclusters packed with daptomycin. ACS Nano, 2016, 10: 7934-7942

36 Arora S, Jain J, Rajwade JM, et al. Cellular responses induced by silver nanoparticles: In vitro studies. Toxicol Lett, 2008, 179: 93-100

37 Toumey C. Quick lessons on environmental nanotech. Nat Nanotech, 2015, 10: 566-567

38 Sun W, Song W, Guo X, et al. Ultrasensitive detection of nucleic acids and proteins using quartz crystal microbalance and surface plasmon resonance sensors based on target-triggering multiple signal amplification strategy. Anal Chim Acta, 2017, 978: 42-47

39 Shen $\mathrm{M}$, Zheng LR, He W, et al. High-performance oxygen reduction electrocatalysts derived from uniform cobalt-adenine assemblies. Nano Energy, 2015, 17: 120-130

40 Giano MC, Ibrahim Z, Medina SH, et al. Injectable bioadhesive hydrogels with innate antibacterial properties. Nat Commun, 2014, 5: 4095

41 Ding X, Duan S, Ding X, et al. Versatile antibacterial materials: An emerging arsenal for combatting bacterial pathogens. Adv Funct Mater, 2018, 28: 1802140

42 Sun $\mathrm{H}$, Gao N, Dong K, et al. Graphene quantum dots-band-aids used for wound disinfection. ACS Nano, 2014, 8: 6202-6210

43 Simončič B, Klemenčič D. Preparation and performance of silver as an antimicrobial agent for textiles: A review. Textile Res J, 2016, 86: 210 223

44 Fang G, Li W, Shen X, et al. Differential Pd-nanocrystal facets demonstrate distinct antibacterial activity against gram-positive and gram-negative bacteria. Nat Commun, 2018, 9: 129

45 Cheng AA, Ding H, Lu TK. Enhanced killing of antibiotic-resistant bacteria enabled by massively parallel combinatorial genetics. Proc Natl Acad Sci USA, 2014, 111: 12462-12467

46 Brown ED, Wright GD. Antibacterial drug discovery in the resistance era. Nature, 2016, 529: 336-343

47 Blaskovich MAT, Hansford KA, Gong Y, et al. Protein-inspired antibiotics active against vancomycin- and daptomycin-resistant bacteria. Nat Commun, 2018, 9: 22

48 Nederberg F, Zhang Y, Tan JPK, et al. Biodegradable nanostructures with selective lysis of microbial membranes. Nat Chem, 2011, 3: 409_ 414

49 Liu X, Yan Z, Zhang Y, et al. Two-dimensional metal-organic framework/enzyme hybrid nanocatalyst as a benign and self-activated cascade reagent for in vivo wound healing. ACS Nano, 2019, 13: 52225230

Acknowledgements This work was supported by the National Natural Science Foundation of China (21703230, 21635007 and 21721003), and K.C. 
Wong Education Foundation.

Author contributions Wang $\mathrm{W}$ and $\mathrm{Yu} \mathrm{B}$ designed and engineered the samples; Wang W performed the experiments; Wang W and Yu B performed the data analysis; Wang $\mathrm{W}$ and Sun $\mathrm{W}$ wrote the paper with support from Jiang $\mathrm{C}$ and $\mathrm{Lu} \mathrm{L}$. All authors contributed to the general discussion.

Conflict of interest The authors declare that they have no conflict of interest.

Supplementary information Supporting data are available in the online version of the paper.

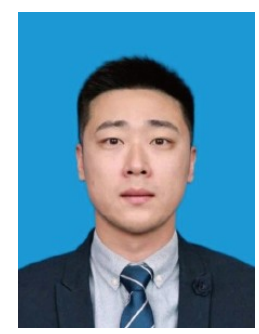

Wei Wang received his BSc (2015) from the College of Chemistry, Northeast Normal University. He is pursuing his $\mathrm{PhD}$ degree under the direction of professor $\mathrm{Lu}$ at Changchun Institute of Applied Chemistry, Chinese Academy of Sciences (CIACCAS). His current research interests focus on the development of novel functional materials for antibacterial applications.

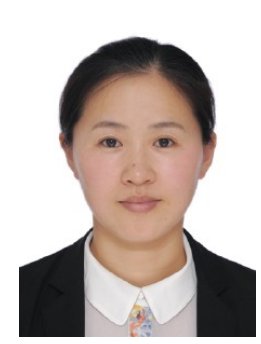

Chunhuan Jiang received her MSc degree (2011) from Harbin Institute of Technology. She is currently an associate professor at CIACCAS. Her research interest focuses on the development of novel nanoprobes for biomedical theranostic, and the application of Raman spectroscopy in the regions of surgical navigation and environmental contaminant analysis.

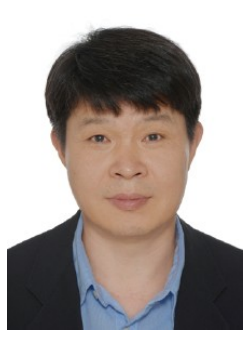

Lehui Lu received his MSc (2000) and PhD (2003) degrees from the CIACCAS. He carried out his postdoctoral research at Hamburg University (20032005) and Kwansei Gakuin University (2005-2007). $\mathrm{He}$ is currently a professor and deputy director at CIACCAS. His research focuses on nano-structured functional materials for energy, biomedical and environment-related applications.

\section{生物启发的纳米蜘蛛网结构用于细菌的高效捕获和 杀伤}

王唯 1,2 , 于滨 ${ }^{1,3}$, 孙文博 ${ }^{1,4}$, 姜春环 ${ }^{1,2 *}$, 逯乐慧 $1,2^{*}$

摘要 具有广谱抗菌活性的纳米抗菌剂的出现是抗生素的一次革命性 进化, 然而其细菌捕获能力及杀菌效率低致使它仍然无法达到商品化 应用的要求. 受到蜘蛛捕虫行为的启发, 本研究设计了一种基于银和腺 嘌呤配合物合成的蜘蛛网状的纳米抗菌材料, 从而实现高效的细菌捕 获和杀伤. 这种纳米蛛网材料能够通过静电相互作用并利用其网状的 形态特征有效地吸附并捕获细菌, 此外, 其物理溶膜机制和活性氧杀菌 机制协同作用也使其具备更优异的抗菌活性. 由该纳米蛛网材料制成 的创可贴与市售的商品化创可贴相比，对耐药革兰氏阴性的大肠杆菌 和耐药革兰氏阳性的金黄色葡萄球菌均表现出更优异的抗菌效果. 